\title{
A Review of Last 10 Years' Work in the Department of Biochemistry in Nihon University School of Dentistry
}

\author{
by \\ Atsushi OSHIKANE*
}

\begin{abstract}
The present review attempts to describe the research activities of OSHIKANE Laboratory, one of the laboratories in the Department of Biochemistry, Nihon University School of Dentistry, Tokyo. Having been established in 1938, it enjoys the longest history among the dental schools in Japan as a biochemical laboratory. Prof. OSHIKANE, author of the paper, is the director of the Laboratory and is known by his recent book 'Pathological Biochemistry' (Kyodo Medical Publishing Co., Tokyo, 1961) among many other papers in learned journals. He was chosen as a member of trustee board in 1951, the first delegate from the realm of dentistry, for the Japanese Biochemical Society which is the only authoritative body composed of all the biochemists throughout the country.
\end{abstract}

\section{Organic Components of Dental Hard Tissues}

Researches in the organic components in dental hard tissues were begun as early as in 1939 by OshikANE [1], [2]. Since 1951, works have been chiefly done in the soluble proteins of human dentine [3], [4], [5], as well as in mucoprotein [6], [7], [8], [9], insoluble protein [10] and acid-insoluble collagen [11] of sperm-whale dentine, with their isolations, determinations of amino acid composition and analyses of polysaccharide portion. As regards the soluble protein of human dentine, a comparative study was undertaken between amino acid compositions collected from the normal dentine and carious dentine (the so-called softened dentine) [5]. The hardening process in which dentinal mucoportein was combined with soluble $\mathrm{Ca}\left(\mathrm{H}_{2} \mathrm{PO}_{4}\right)_{2}$ was quantitatively measured and investigations made into influences of citrate and other organic salts having relation to the TCA cycle and its environs on the hardening process. As a result, citrate is known to possess an action to promote the hardening of combination between dentinal mucoprotein and $\mathrm{Ca}\left(\mathrm{H}_{2} \mathrm{PO}_{4}\right)_{2}$ [9].

Among the organic components other than protein, studies have been done on the isolation and purification of an iron-containing brown pigment which is found in sperm-whale dentine [12], [13], [14]. This pigment which possesses $0.28 \% \mathrm{Fe}^{\#}$ is thought to contain in its molecules a compound of peptide probably having tyrosine, histidine and arginine. Absorption maximum in ultraviolet area and maximal energy wave of fluorescence were measured in this pigment [14], this brown pigment being inferred to exist in the teeth in a combined state with protein.

* 押鏡 篤: D. D. S., M. D., D. M. Sc., Director of OSHIKANE Laboratory, Dept. of Biochemistry, Nihon Univ. School of Dentistry 
Further concerning the foaming phenomena (foaminess, life-time of foam, velocity constant of foam collapse, etc.) of soluble extracts taken from dental hard tissues, various measurements have been made. The findings on the soluble extracts of dental hard tissues were contrasted with those of other tissues such as bone, muscle, mucous membrane, skin, uterus, etc., prepared in the same total $\mathrm{N}$ concentration as for those of dental hard tissues. As a consequence of this series of experiments, it came to be established that the character which may be termed as organ specificity is found in the curves of foaming phenomena and that specific fluctuations are observable with various foaming phenomena of soluble extracts from those tissues, depending upon the freshness of samples. This finding should prove of value in the application of forensic medicine [15].

\section{Dental Caries}

In the field of dental carious researches, an objective was set in the early years of the Laboratory to discover new facts on dental caries on the basis of findings in various foaming phenomena described above. For instance, experiments and measurements were made for fluctuations taking place in foaming due to the fermentational process of sugar in saliva or putrefaction of dentinal components by caries bacteria, efforts being made to elucidate the phenomena together with their chemical and physicochemical changes in the identical samples [16], [18], [19], [20].

On the other hand, inquiries were made into possible correlationship between the properties of normal saliva and susceptibility to dental caries of that person. What is considered noteworthy in these inquiries is the finding that the foaming phenomena of whole resting saliva, particularly its foaminess (foam volume) can be used as a good criterion to diagnose a person's susceptibility to dental caries, though not necessarily carious activity [17], [51], [53], [69].

For the general conclusion points to the fact that irrespective of age and sex in all the seasons, those who have suffered dental caries (including those which were already cured) have a lower foaminess of their resting saliva than that of normal dental condition. This finding is to be taken as accounting for the constitutional factors which play a part in the formation of dental caries. Another interesting discovery seems to be that the whole resting saliva of dental carious patients is found to have lower $\mathrm{O}_{2}$ uptake and its decolorizing power of methylene blue (glucose was used as substrate) is also weaker than the case of normal persons [20], [21], [71].

After these studies the author received impetus from the proteolysis-chelation theory of dental caries propounded by SCHATZ \& MARTIN of United States and fundamental studies on the mechanism of tooth decalcification, regarding the chelating action in particular, in dental caries have been engaged up to date [22], [23[, [24].

Part of our activities in this field was reported by Dr. SCHATZ as "Caries Research in Japan and England: A Review of Three Important Papers" (The New York State Dent. J., $27: 301$. 1961). The students of the present author are currently engaged in the chemical changes of collagen in the caries phenomenon of dentinal region itself.

We are not losing sight of importance claimed by fermentation of lactic acid in oral cavity. Biochemical mechanism of strong ability for lactic acid fermentation was investigated concerning Candida albicans which are isolated from the dental caries regions with a high percentage [25], [26], [27], [28]. 


\section{Dental Pulp and Pulpitis}

Our Laboratory is at present. most attentively concerned with this branch of research activities and our previous efforts are highly estimated as one of four high peaks in the biochemical studies on dental pulp in the world, being recognized as the most advanced in Japan [42], [43].

In 1952 we first undertook investigations into the electrophoretic analysis as well as amino acid analysis of dental pulp proteins and our attention was in particular directed to pathological changes of pulp proteins in experimentally induced mandibular osteomyelitis [29], [30], [31]. Further, the putrefactive process of dental pulp components with foaming phenomena as criteria was studied [32].

As a result of investigations into oxidation-reduction enzyme systems of dental pulp components, emphasis came to be placed upon the mechanism of succinic oxidase system which is recognized to be the most powerful among them [33], [34], [35], [36], [37], [41]. Some subsidiary works were also made [38], [39], [40].

The Japanese are noted for the dexterity of their fingers and this forte was fully utilitized in dealing with various aspects of dental pulp tissues: (a) odontoblastic layers were removed off the frozen portion of pulp tissues and their enzyme activity was compared with that of proper pulp cell layers, ( $b$ ) through cutting dental pulps of rabbit into little segments, local differences were measured in enzyme activity and its correlation with succinic oxidase system for the hard tissue formation was studied, (c) various sample forms such as shavings, mince and mangled pulps were used for the measurement of oxidation-reduction enzyme systems of pulp tissues, and (d) cavity preparations were made on rabbit teeth per usual clinical method and non-bacterial pulpitis was experimentally induced by thc application of various toxic substances inside, pursuing the behavior of succinic oxidase system in the chronological manner [41].

Another noteworthy result obtained in our efforts in dental pulp biochemistry is that the author and his associates were the first in the world that succeeded in purifying alkaline phosphomonoesterase contained in pulp tissues [44], [45]. Enzymes in dental pulps of rabbits are found to be more potent in activity than those of other animals and for this reason, rabbit dental pulp was chosen for experimental specimen. Based on the modified MORTON's method, a yield of as much as $16 \%$ of purified sample was obtained having 89 times relative activity, and various enzymological measurements were made on this sample. Although biochemical properties of enzymes were clarified, their physiological aspect still remains to be explored at a future date.

\section{Periodontosis (the so-called Pyorrhea Alveolaris)}

Our efforts in this branch of dental science have not been much active [46], [47], [48], [49]. However, one finding which is of interest is the fact that some toxic substances (which do not exist in the normal urine) are detected in urine of severe periodontotic patients which highly inhibit the cardiac activity of animals. Chemical composition of these toxic substances is found to be a mixture of histidine, alanine and glutamic acid [48]. Each one of the amino acids, above noted, shows almost no cardiac toxicity individually. 


\section{Saliva}

Various forms of human such as whole saliva, parotid saliva, resting saliva, dietary reflex saliva and pilocarpine-stimulated saliva have been studied with particular reference. to their foaming phenomena, together with their chemical and physico-chemical properties [50], [51], [53], [55], [56], [57], [58], [59], [60], [62], [63], [64], [65], [66], [67], [68], [69], [70], [73], [74]. As these studies are peculiar to our Laboratory, the author has given a summary of these findings [61]. Of this series of related studies, what is most interesting from the views of constitutional medicine as well as hygiene point is the behavior of foaming saliva in terms of age and seasons. That is to say, the general conclusion seems to be that the younger a person is, the easier and greater is his whole saliva in regard to its foaminess (measured by its foam volume) and persistency (measured by its life-time), that the whole saliva is easier to form foams in summer time than in other seasons (the greatest persistency of foams is shown in winter), and that salivary foaminess is not influenced by the temperature at the time of an experiment but influenced wholly by the seasons [51], [53], [62], [68]. As already referred to earlier, there is definitely found a correlationship between the foaminess of whole resting saliva and susceptibility to dental caries, which serves as a reliable criterion in the determination of a carious case [53], [69].

Research efforts have also been made to various sub-problems arising out of the foaming phenomena of saliva [52], [54], [55], [72]. A thin film which constitutes foam grains or bubbles was investigated with regard to its electric properties [73], [74]. This study was done preliminary to a difficult subject of foam formation for its physicochemical elucidations.

There are known 3 methods by which foam is generated; pneumatic (gas dispersion), shaking and stirring, and we adopted the former two methods under cumulative addition of $\mathrm{NaCl}$ solution or buffer solution in order to measure "the total foam volume", having arrived at the belief that this shaking method represent most faithfully the foaminess of biological fluids.

\section{Urine}

Our main concern with urine is in its aspect of foaming phenomena and it has come to be known that fatigue of a person has much to do with a high degree of his. urinary foaminess. A criterion has been worked out and is known under the designation of OSHIKANE-KISHI-TAMURA-YOSHIDA method for fatigue estimation. By the application of this method it is established that urine after physical exercises shows a higher degree of foaminess than that before physical exertions, returning to the normal level after sufficient rest [75], [76]. It has further become known that this method is applicable to measure the amount of stress under surgical invasions [77]. By the same token, this method has been also applied to the estimation of various industrial fatigues (heavy, light labors, etc.) with favorable results [78], [79].

In parallel to our experiments with urine, efforts were made for the purpose of clarifying urinary components responsible for the generation of foaminess and foam stability. As a result under this heading of investigations, urinary mucoprotein isolatable by the method of ANDERSON et al. and the so-called nubecula substance (which is also recognized as a sort of mucoprotein), are found to be principal factors in the generation of foaming phenomena of urine. When these substances are compounded 
with other components, foaming phenomena of urine will take place, an instance being that a foaminess due to inhibition of foam formation by urinary pigments [78], [79].

In addition to mucoprotein, there are found though in minute quantities common protein and bile acid salts (glycocholate in particular), all playing a part in foaming phenomena. Mucoprotein and common protein are known to enhance the foaminess of urine and strengthen the foam stability, while bile acid salts render foam grains unstable, though possessing an action to enhance the foaminess. Phosphate, chloride, urate and other components found in urine are regarded as more or less playing a part in the foaming phenomena [75], [76], [77].

Among fatigue estimation methods for the measurement of mucoprotein predominantly existing $\mathrm{n}$ urine, DONAGGIO reaction and its many modifications are wellknown. Although these methods are excellent in the estimation of muscular fatigue of acute nature, they leave much to be desired in the estimation of chronic fatigue. This has been experimentally ascertained with the modified DONAGGIO method, where fatigues of light laborers were compared in terms of hourly and daily accumulations with the result that the method proved far more accurate in the former [79]. An examination of the foaminess of urine collected from college students prior to the commencement of term-end examinations has revealed that since this method sharply responds to any kind of fatigues it has a possibility of being applicable for the mental fatigue estimation to some degree (this result is contained in an unpublished paper).

\section{Proteins and Enzymes}

Some contributions have been made by our staff to this branch of study. First in the order of publication are the clinical observations on the fluctuation of quantity of serum protein fractions and amylase activity of blood and saliva [80], [81], [82]. Secondly, we could describe the behaviors of protein denaturation and its reverse process in the light of its foaminess and foam collapse [83], [84], [88]. Thirdly, a couple of new phenomena (periodical fluctuations of foaminess, surface viscosity, and dynamic surface tension) seen in the hydrolytic process of protein were brought to light [85], [90], [91]. Fourthly, researches were done in the enzyme purification by froth fractionation [86], [89], together with some subsidiary works along the line [87].

The author is going to touch briefly on what is considered of utmost importance. Three subjects of protein, denaturation and foam have a very close relation with one another but previous efforts have been somewhat lacking into the clarification of this close relationship. An authoritative book, "Foams" (1953) written jointly by BIKERMAN, PERrI, SOOTH \& CURRIE, makes no mention of this relationship at all, we find only a cursory treatment of this matter in "Schaum" (1953) by MANEGOLD and "The Proteins", (1953-1954) by NEURATH \& BAILEY. We undertook studies on heat denaturation of respective solutions of albumin, pseudoglobulin and $\gamma$-globulin of horse serum and egg albumin as well as HAMMARSTEN casein and on its reverse process, arriving at the fact that these values can be very accurately established in terms of their foaming phenomena and thus substantiated a scientific ground for a close relationship among protein, denaturation and foam [83], [84], [88]. In this attempt, we had dispensed with a denaturation method by the addition of denaturing substances because of the fact that these denaturing substances themselves interfere with foaming phenomena.

No fact has been hitherto published dealing with the periodical changes in hydro- 
lytic process of protein. However, we conceived a first hint in connection with the periodical fluctuation of foaming phenomena in $\mathrm{HCl}$-hydrolysis of saliva [55] and studied $\mathrm{HCl}$-hydrolysis of total protein, albumin and total globulin of horse serum and egg albumin as well. As a consequence, three properties of foaminess, surface viscosity and dynamic surface tension taking place in hydrolysate solutions were found to be intimately associated with one another and show remarkable periodical fluctuations of special kind [85], [90], [91]. It is thought that this finding will prove of value in further study of protein for its hydrolytic process or structure.

In concluding a review of last 10 years' research work performed by Prof. OsHIKANE and his associates in the Department of Biochemistry, Nihon University School of Dentistry, they have made efforts to introduce biochemical methods into the area of dentistry to clarify the physiological and the pathological aspects of dental hard tissues, dental pulp and saliva, and also have turned their attention from biochemical point of view to foaming phenomena, hitherto restricted more or less to beer brewery, soap manufacturing and foaming extinguisher industries, with the spirit of pioneers to elucidate their academic significances and their applications.

\section{References}

[1] Oshikane, A.: Studies on the Organic Components of the Sound Enamel. J. Nihon Univ. Dent. Res. Soc., 19 : 313, 355 (1939)*

[2] Oshikane, A. \& Kochi, Z.: Studies on the Organic Components of Human Dentine. J. Nihon Univ. Dent. Res. Soc., 19: $577(1939)^{*}$

[3] Moriya, S. : Study on the Organic Components of Dentine. Bull. 1950 Congr. Jap. Dent. Assoc., p. $161(1951)^{*}$

[4] Moriya, S., Asano, T. \& Kikuchi, T. : Amino Acids in Sound Human Teeth. J. Dent., 5(4) : $18(1951)^{*}$

[5] Moriya, S.: Studies on Soluble Proteins in Human Dentine, especially on Their Amino Acid Composition. Nihon Univ. Med. J., 10: 167 (1951)*

[6] Kanbe, K., Yamazaki, T., Mogi, H. \& Yokokawa, T. : A Phenomenon Resembling RIESEGANG's Phenomenon Observed in the Reaction between Dentinal Mucoprotein and Primary Calcium Phosphate. J. Nihon Univ. Dent. Res. Soc., 32 : 224 (1958)*

[ 7 ] Nolkura, T., Oshikane, A., Okano, T. \& Hasegawa, H. : Biochemical Application of Metachromasia. J. Nihon Univ. Dent. Res. Soc., 31 : 140 (1957)*

[8] Mirsui, O., Kono, H. \& ORII, F. : Notices in the Identification of Sugars Using Anthrone Reagent. J. Nihon Univ. Dent. Res. Soc., $32: 230(1958)^{*}$

[9] KanBe, K. : Properties of Dentinal Mucoprotein with Special Reference to its Combination with Calcium and Phosphoric Acid. Nihon Univ. Med. J., 19: 485 (1960)*

[10] Saito, T., Kira, K., Kimizuka, T. \& Noikura, T. : Amino Acid Composition of Insoluble Protein in Human Dentine. J. Nihon Univ. Dent. Res. Soc., 35 : 291 (1961)*

[11] Saito, T. \& Oshikane, A. : Amino Acid Composition of Acid-Insoluble Collagen in Sperm Whale Dentine. J. Jap. Biochem. Soc., 33: 704 (1961)*

[12] Oshikane, A., Ogawa, M., Ogawa, K. \& Nitta, K. : Dentinal Pigment and its Role. J. Nihon Univ. Dent. Res. Soc., 31 : $140(1957)^{*}$

[13] Ogawa, M., Shimizu, T., Takahashi, H. \& Imazawa, S. : Purification of Dentinal Pigment with Paper Chromatography. J. Nihon Univ. Dent. Res. Soc., $32: 225$ (1958)*

[14] Ogawa, M. : Studies on a Pigment in Teeth. Nihon Univ. Med. J., 19: 703 (1960)*

[15] Oshikane, A., Akizuki, T., Sugita, Y. \& Fuse, Y. : Foaming Phenomena of Animal Organ Extract Solution. Nihon Univ. Med. J., 12 : 92, 95 (1953)* 
[16] Oshikane, A., Akizuki, T., Sugita, Y. \& Fuse, Y. : Foaming Phenomena as the Criteria in the Studies of the Fermentation in Saliva, the Putrefaction of Dentine, and the Putrefaction of Dental Pulp. J. Jap. Biochem. Soc., 26:407, 571 (1954) ; 27 : 355 (1955)*

[17] Sakamoto, K., Asano, T. \& Sato, G.: On the Correlation between the Foaming Phenomena of Human Saliva and the Dental Caries Susceptibility. J. Nihon Univ. Dent. Res. Soc., Revived Ed. No. 2, p. $1(1951)^{*}$

[18] SugitA, Y.: Studies on the Putrefactive Process of Dentinal Components Using the Foaming Phenomena as the Criteria. Nihon Univ. Med. J., 15: $310\left(1956{ }^{*}\right.$

[19] Sugrta, Y.: On the Putrefactive Process of Dentinal Components. J. Nihon Univ. Dent. Res. Soc., $30: 24(1957)^{*}$

[20] Akizuki, T.: On the Relation between the Properties of Saliva and the Susceptibility to Dental Caries. Nihon Univ. Med. J., $16: 2053(1957)^{*}$

[21] AkIZuki, T. : Studies on Relations between Saliva and Its Susceptibility to Dental Caries. Dent. J. Nihon Univ., 1: 31 (1958; (in English)

[22] SAIto, T. : Fundamental Studies on the Decalcification Mechanism of Teeth in Dental Caries. (I) On the Chelating Agents. J. Nihon Univ. Dent. Res. Soc., 31: 71 (1957)*

[23] Saito, T. \& Oshikane, A. : Fundamental Studies on the Decalcification Mechanism of Teeth in Dental Caries. (II). Jap. J. Oral Biol., 2 : $20(1960)^{*}$

[24] Saito, T., Oshikane, A. \& Suzuki, H. : Experimental Studies on the Decalcification of Teeth. J. Nihon Univ. Dent. Res. Soc., $31: 141(1957)^{*}$

[25] Oshikane, A., Kon, H., Imai, O. \& Asano, F. : Study of Lactic Acid Fermentation by the Yeast Isolated from Dental Caries Regions. J. Nihon Univ. Dent. Res. Soc., 31 : 142 (1957)*

[26] Kon, H., TANakA, N. \& SaWARA, Y. : Lactic Acid Fermentation by Candida albicans Isolated from Dental Caries Regions. J. Nihon Univ. Dent. Res. Soc., 32 : 230 (1958)*

[27] Kon, H., Aoshima, S. \& Sakamoto, E. : Lactic and Pyruvic Dehydrogenases of Candida albicans Isolated from Dental Caries Regions in Comparison with C. albicans from Other Regions. J. Nihon Univ. Dent. Res. Soc., 32: $230(1958)^{*}$

[28] Kon, H. : Supplementary Studies on the Organic Acid Oxidation and the Lactic Acid Fermentation by Candida albicans Isolated from the Dental Caries Region with Special Reference to Pathogenic Candida albicans. Nihon Univ. Med. J., 19: $690(1960)^{*}$

[29] Oshikane, A. \& Sato, G. : Electrophoretic Analysis and Amino Acid Analysis of Dental Pulp Protein. Nihon Univ. Med. J., 11: $972(1952)^{*}$

[30] Oshikane, A. \& Sato, G. : The Attitude of Serum Protein and Dental Pulp Protein in Experimental Mandibular Osteomyelitis. Nihon Univ. Med. J., 11 : $978(1952)^{*}$

[31] Sato, G. : Dynamic State of Serum Protein and Dental Pulp Protein in Mandibular Osteomyelitis of Dogs. Nihon Univ. Med. J., 12: $709(1953)^{*}$

[32] Fuse, Y. : Foaming Phenomena as Criteria in the Study of the Putrefactive Process of the Dental Pulp Components. Nihon Univ. Med. J., 15 : $403\left(1956{ }^{*}\right.$

[33] Oshikane, A., Okubo, H., Kira, N. \& KIRA, K. : Oxidation-Reduction Enzyme System of Dental Pulp Tissue. J. Nihon Univ. Dent. Res. Soc., 31 : $140(1957)^{*}$

[34] Oshikane, A. \& Okubo, H. : Studies on the Metabolic System of Dental Pulp Tissue. (I). J. Jap. Biochem. Soc., 30: $898(1958)^{*}$

[35] Kira, K. \& Oshikane, A. : Studies on the Metabolic System of Dental Pulp Tissue. (II) J. Jap. Biochem. Soc., 31: $628(1959)$; (III). ibid., $32: 625(1960)^{*}$

[36] Okubo, H. : Findings on the Tissue Respiration and the Oxidation-Reduction System of Dental Pulp. Nihsn Univ. Med. J., 18 : 1550 (1959)*

[37] Kira, K. \& Oshikane, A. : On the Succinic Oxidase System of Dental Pulp. J. Nihon Univ. Dent. Res. Soc., 32 : $183(1958)^{*}$

[38] Kira, K., Kinoshita, S., Habu, Y. \& Moteki, H. : An Invention for Precise Measurement of Water Content and Dry Weight of Dental Pulp Tissue. J. Nihon Univ. Dent. 
Res. Soc., $32: 225(1958)^{*}$

[39] Kira, K., Kimizuka, T., Saito, T. \& Noikura, T. : On the Influence of Freeze-Drying Storage of Dental Pulp on Its Activity of Succinic Oxidase System. J. Nihon Univ. Dent. Res. Soc., $35: 280(1961)^{*}$

[40] Kimizuka, T., KirA, K., Saito, T. \& Noikura, T: : On the Blood Quantity in Rabbit Pulp and Its Attitude in the Inflammation of Pulp. J. Nihon Univ. Dent. Res. Soc., 35 : $286(1961)^{*}$

[41] KrRA, K. : Studies on the Succinic Oxidase System of the Dental Pulp Tissue. J. Nihon Univ. Dent. Res. Soc., 35 : $309(1961)^{*}$

[42] Oshrkane, A. : Biochemistry of Dental Pulp and Its Clinical Significance. Jap. Dent. Outlook. 18: $665(1961)^{*}$

[43] Oshikane, A. : Biochemistry of Dental Pulp and Pulpitis. Jap. J. Oral Biol., 3: 90 (1961)*

[44] Kimizuka, T. \& Oshikane, A. : Purification of Phosphomonoesterase in Dental Pulp. (I). J. Jap. Biochem. Soc., 33 : $616(1961)^{*}$

[45] Kimizuka, T. : Purification of Alkaline Pnosphomonoesterase of Dental Pulp Tissue. J. Nihon Univ. Dent. Res. Soc., 36: $1(1962)^{*}$

[46] Taguchi, K., Wada, K., Asano, T. \& Moriya, S. : Periodontosis and Cholinesterase Activity. (I). J. Nihon Univ. Dent. Res. Soc., $28(2): 7(1954)^{*}$

[47] TAguchi, K., WAdA, K. \& TAmura, Y. : Periodontosis and Cholinesterase Activity. (II). ibid. $29: 79(1955)^{*}$

[48] TAguchi, K. : On the Pharmacological Actions of Amino Acid Mixtures to the Excised Toad-Hearts. (I). Action of Amino Acid Mixture in the Urine of Periodontotic Patients. J. Nihon Univ. Dent. Res. Soc., 33 : $40(1959)^{*}$

[49] Oshikane, A. : Periodontosis (so-called pyorrhea alveolaris) and Oxidative Insufficiency. J. Jap. Dent. Assoc., 14: $885(1962)^{*}$

[50] Kikuchi, T., Sato, G., Yamada, N. \& Kishida, J. : Fundamental Study of Foaming Phenomena of Saliva. Bull. 1950 Congr. Jap. Dent. Assoc. p. $174(1951)^{*}$

[51] Oshikane, A. \& Sakamoto, K. : Studies of Foaming Phenomena of Human Saliva. Nihon Univ. Med. J., 11: $63(1952)^{*}$

[52] Kikuchi, T. \& Hino, Y. : Amino Acid Composition of Saliva and Salivary Mucine. Jap. Dent. J., 6 : $14(1952)^{*}$

[53] Sakamoto, K. : Hygienic Studies of Foaming Phenomena of Human Saliva. Nihon Univ. Med. J., 11 : $108(1952)^{*}$

[54] Shimada, T., Mimura, R. \& Kikuchi, T. : Relation of the Viscosity of Human Saliva to the Mucine Content in Saliva. J. Tokyo Dent. Coll., 52: 35 (1952)*

[55] Sakamoto, K., Asano, T. \& Sato, G. : On the Fluctuation of the Foaminess and the Foam Stability Observed during the HCl-Hydrolysis of Human Saliva. Jap. Med. J., 1455 : $867(1952)^{*}$

[56] Oshikane, A. \& Sato, G. : Constitutional Observation of Foaming Phenomena of Human Saliva after Injection of Autonomic Nervous Poisons. Nihon Univ. Med. J., 11: 666 (1952)*

[57] Oshikane, A., Sato, G. \& Asano, T. : On the "Coagulation" of Salivary Foam after Long Time Shaking. Nihon Univ. Med. J., 11 : $672(1952)^{*}$

[58] Oshikane, A., Asano, T. \& Kikuchi, T. : Biochemical Studies of Foaming Phenomena of Saliva. Nihon Univ. Med. J., 11 : $972(1952)^{*}$

[59] Oshikane, A., Yamada, N. \& Kishida, J. : Studies on the Foaming Phenomena of the Resting Saliva and the Dietary Reflex Saliva. (I). Nihon Univ. Med. J., 11: 979 (1952);

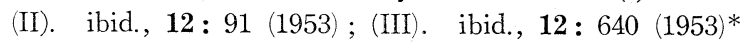

[60] Oshikane, A. : Studies on Foaming Phenomena of Dietary Reflex Saliva. J. Jap. Biochem. Soc., $24: 11(1953)^{*}$

[61] Oshikane, A. : The Outline of the Studies on Salivary Foam in Our Laboratory. J. 
Jap. Dent. Assoc., 5 : $442(1953)^{*}$

[62] Oshikane, A., Sakamoto, K., Asano, T., Sato, G., Yamada, N. \& Kishida, J. : Constitutional Studies of Foaming Phenomena of Saliva. Jap. J. Oral Hyg., 2 : $22(1953)^{*}$

[63] Kishi, N., Tamura, Y., Yamada, N. \& Kishida, J. : Foaminess and Elementary Bubble Life-time of Human Saliva with Special Reference to Surface Tension and Viscosity of It. J. Jap. Dent. Assoc., 6 : $157(1953)^{*}$

[64] KikUCHI, T. : On the Relation between the Foaminess of Human Saliva and Its Chemical Components. Nihon Univ. Med. J., 12: $758(1953)^{*}$

[65] Asano, T. : Effects of Various Substances upon the Foaminess of Human Saliva. Nihon Univ. Med. J., 13 : $690(1954) *$

[66] Yamada, N.: Effects of Dietary, Acid and Pilocarpin Stimulations on Foaminess of Saliva. Nihon Univ. Med. J., 14 : 1673 (1955)*

[67] KishidA, J. : Effects of Dietary, Acid and Pilocarpin Stimulations on Elementary Bubble Formation of Saliva. Nihon Univ. Med. J., 15: $25(1956)^{*}$

[68] Sakamoto, K.: Hygienic Study on Foaming Phenomenon of Human Saliva. Part I. Sex, Age, Seasonal and Other Factors Affecting Foaming Pnenomenon of Human Saliva. Dent. J. Nihon Univ., 1: 23 (1958) (in English)

[69] Oshikane, A. : Hygienic Study on Foaming Phenomenon of Human Saliva. Part II. Relation of Foaming Phenomenon with Various Physiological, Pathological and Biochemical Factors. Dent. J. Nihon Univ., 1 : 113 (1958) (in English)

[70] KiKUCHI, T. : Relationship between Foaminess of Saliva and Its Chemical Components. Dent. J. Nihon Univ., 1: 105 (1958) (in English)

[71] Akizuki, T. : Studies on Relations between Saliva and Its Susceptibility to Dental Caries. Dent. J. Nihon Univ., 1: 31 (1958) (in English)

[72] Okubo, H. \& ARAI, E. : Specific Gravity and Surface Tension of Human Saliva with Reference to Mucine Content in Saliva. J. Nihon Univ. Dent. Res. Soc., 31: 225 (1958)*

[73] Noikura, T., Okochi, T. \& Kato, M. : Electric Properties of the Thin Film of Saliva. J. Nihon Univ. Dent. Res. Soc., 33 : 216 (1959)*

[74] Noikura, T. \& Oshikane, A. : Thin Film of Saliva and Its Significance in Dentistry. (I). Jap. J. Oral Biol., 2 : 21 (1960)*

[75] Oshikane, A., Kishi, N. \& Tamura, Y.: A New Method for Fatigue Estimation Using Foaming Phenomena of Urine as Criteria. (I). J. Jap. Biochem. Soc., 24: 226 (1952); (II). ibid., 25 : 232 (1953); (III). Nihon Univ. Med. J., 13: 206 (1954); (IV). J. Jap. Biochem. Soc., 27 : 355 (1955)*

[76] Kishi, N. : A Method for Fatigue Estimation Using Foaminess of Urine as a Criterion. Nihon Univ. Med. J., 13 : $1773(1954)^{*}$

[77] TAMURA, Y.: Fluctuation of Foaming Phenomena of Urine with Special Reference to Urinary Components under Surgical Stress. Nihon Univ. Med. J., 16 : 2646 (1957)*

[78] Oshikane, A. \& Yoshida, T. : Further Studies on Estimation of Fatigue by the Foaming Phenomena of Urine. (I). Med. Biol., 45 : 74 (1957); (II). ibid., 45 : 191 (1957); (III). ibid., 48: 14 (1958); (IV). J. Jap. Biochem. Soc., 30 : $893(1958)^{*}$

[79] Yoshida, T. : Comparative Studies on the Fatigue Estimation Methods Pertaining to the Urinary Mucoproteins. Nihon Univ. Med. J., 18: $587(1959)^{*}$

[80] Oshikane, A., Sato, G., Yamada, N. \& KishidA, J. : Effects of Experimental Tooth Extractions upon Serum Proteins. Nihon Univ. Med. J., 11: 589 (1952)*

[81] Oshikane, A. \& Sato, G. : Relations between Serum Protein Curves and Serum Foaminess Curves in Experimental Mandibular Osteomyelitis. Nihon Univ. Med. J., 11 : 1069 $(1952)^{*}$

[82] Oshikane, A., Hino, Y., Yamada, N. \& Kishida, J. : Foaminess and Amylase Activity of Human Blood under Pilocarpin Injection in Comparison with Those of Saliva. Nihon Univ. Med. J., 11 : $672(1952)^{*}$

[83] Oshikane, A. \& Ebihara, K. : Studies on the Denaturation of Serum Proteins Using 
Foaming Phenomena as Criteria. (I). J. Nihon Univ. Dent. Res. Soc., 29 : 174 (1955); (II). J. Jap. Biochem. Soc., 28: 815 (1956); (III). ibid., $30: 398$ (1958)* $^{*}$

[84] Oshikane, A. \& Ebihara, K. : Foaming Phenomena of Denatured Protein Solutions. (I). Med. Biol., $47: 153$ (1958); (II). ibid., $47: 157(1958)^{*}$

[85] Oshikane, A. \& ARAr, E. : Studies of Hydrolytic Process of Proteins Using Foaming Phenomena as Criteria. J. Jap. Biochem. Soc., 29: $636(1957)^{*}$

[86] Sato, T., Shiba, R., Yamamoto, H., Kuroiwa, S. \& Takeuchi, S. : Purification of Enzymes by Froth Fractionation. J. Nihon Univ. Dent. Res. Soc., 32 : 223 (1958)*

[87] Kanbe, K., Sato, Y., Hisamatsu, I. \& YadA, Y. : An Invention for Measurement of the Hardness of the Soft Colloidal Substances from the Biological Sources. J. Nihon Univ. Dent. Res. Soc., 32: $230(1958)^{*}$

[88] EBIhARA, K.: Heat Denaturation and Foaming Phenomena of Proteins. Nihon Univ. Med. J., $18: 339(1959)^{*}$

[89] Sato, T. : Supplemental Findings in Regard to a Method for Isolation and Condensation of a few Enzymes. Nihon Univ. Med. J., 19: $470(1960)^{*}$

[90] Arai, E. : Periodical Fluctuations Typical of the Hydrolytic Process of Proteins. Nihon Univ. Med. J., 19 : $1065(1960)^{*}$

[91] Arai, E., KirA, K. \& SAITo, T. : Fluctuations of Foam Life-time and of Bubble Diameter during Hydrolysis of Serum Protein with $\mathrm{HCl}$ or $\mathrm{NaOH}$. Jap. Dent. Rep. 6(2): $18(1960) *$

(* Printed in Japanese) 